\title{
Predicting the Environmental Conditions of Megacities
}

\author{
E. V. Sotnikova ${ }^{a}$, A. E. Sorokin ${ }^{a}$, S. N. Bulychev ${ }^{a, *}$, and R. B. Palyga ${ }^{a}$ \\ ${ }^{a}$ Moscow Aviation Institute, Moscow, Russia \\ *e-mail: bulychovsn@yandex.ru
}

Received July 12, 2021; revised July 12, 2021; accepted July 12, 2021

\begin{abstract}
The prediction of the environmental conditions in megacities is considered, taking account of highways. Modernization of smart transportation systems by means of environmental monitoring equipment is analyzed. An environmental monitoring module integrated in a smart transportation system is described.
\end{abstract}

Keywords: megacities, transportation, smart transportation systems, pollution monitoring, atmospheric pollution, air quality, environmental monitoring

DOI: $10.3103 / \mathrm{S} 1068798 X 22010191$

In Moscow, Russia's largest city, roads are the main source of pollution. The environmental impact of automobiles is mainly due to atmospheric emissions of gases and solid particulates, which enter the human organism as a result of respiration. Exhaust gases contain more than 200 components, many of which are highly toxic and carcinogenic. Deposited on the soil, pollution is absorbed by the plants that humans and animals eat.

The quantity of emissions depends on the conditions of road transport [1], such as the specifics of the vehicle (the fuel employed, the engine characteristics, and its design quality), climatic factors (temperature, precipitation, temperature inversions, etc.), and road conditions (the characteristics of the surface, the vehicle speed, traffic volume, and frequency of acceleration and deceleration).

Measures passed by Moscow's city government are intended to reduce the environmental impact of transportation-for example, by improving the engine quality and overall environmental performance of vehicles; by increasing vehicle speeds on the basis of optimal timing of traffic signals and banning heavy trucks from the city; and also by highway construction, road expansion, and the creation of alternative routes [2].

Environmental monitoring provides information regarding urban pollution. This involves tracking pollutant levels, assessing the overall environmental conditions, and predicting the effect of changes in specific factors [3, 4]. Automatic atmospheric monitoring stations are deployed in different parts of the city and along major routes, in order to obtain more detailed information.
In environmental assessment, specific characteristics are calculated: in the case of air monitoring, the index

$$
I_{\text {air }}=\sum_{i=1}^{n}\left(\frac{c_{i}}{E_{c c}}\right)^{K_{i}}
$$

where $c_{i}$ is the concentration of impurity $i$; and the constant $K_{i}$ assesses the risk of the pollutant relative to carbon dioxide. For risk classes $1-4, K_{i}=1.7,1.3,1.0$, and 0.9 , respectively.

Analysis of atmospheric data indicates that the air in Russian cities contains 4-5 powerful pollutants. Therefore, we usually assume that $n=5$. The atmosphere is regarded as clean if $K_{i}<2.5$; slightly polluted if $K_{i}=2.5-7.5$; polluted if $K_{i}=7.5-12.5$; very polluted if $K_{i}=12.5-32.5$; and extremely polluted if $K_{i}>$ $32.5[5]$.

Problems with traffic bottlenecks are addressed by smart transportation systems, which began to be introduced with growth in urbanization, population density, and vehicle volumes. Since 2011, the Moscow Center for Traffic Management has been developing a smart transportation system for management of the congestion and navigability of the city's road network, increasing road safety, and improving transportation services.

The introduction and development of the smart transportation system is currently governed by Moscow government decree 597-PP (August 30, 2017). The system includes information regarding the congestion and condition of the road network and software for the collection, analysis, storage, and updating of such information and also its delivery to interested parties. 


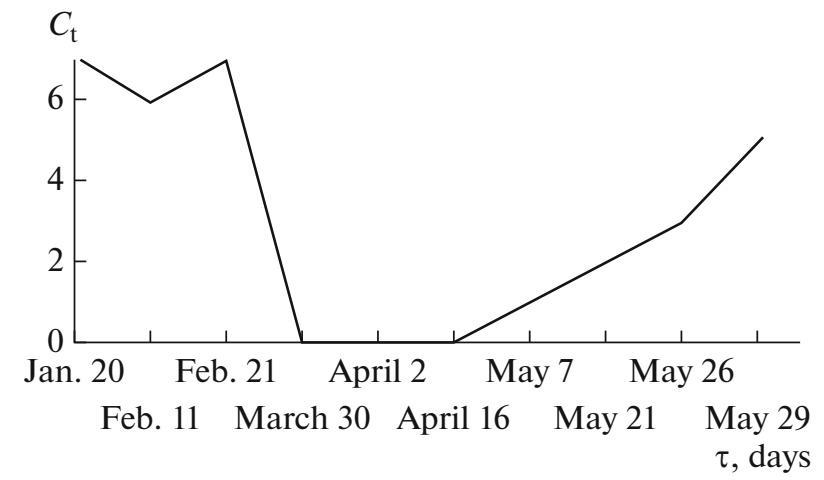

Fig. 1. Change in urban traffic congestion $C_{\mathrm{t}}$ (on a tenpoint scale) according to Yandex.Probki data: $\tau$, time.

Thus, the existing smart transportation system is designed to solve Moscow's traffic problems. It does not include environmental monitoring equipment, although improvement of environmental conditions is an important goal of traffic management $[6,7]$. The environmental monitoring module should combine up-to-date modeling and communications systems so as to predict environmental conditions in the city and improve air quality in timely fashion by appropriate traffic management.

Accordingly, the goals of our research are as follows:

(1) to improve the reliability and practicality of environmental monitoring by using data from the smart transportation system;

(2) to establish the expediency of introducing an environmental monitoring module in the smart transportation system so as to assess environmental conditions in Moscow and predict the impact of changes in the road and highway systems.

\section{RESEARCH METHODS}

The research was conducted in 2020, including the period of the coronavirus pandemic, which severely limited air, railroad, and auto transportation, disrupted manufacturing, and prompted a switch to remote working. Data on road usage and congestion were obtained from the web services Yandex.Probki and Google Maps; data on atmospheric pollution were collected by automatic atmospheric monitoring stations obtained and sent to the Mosekomonitoring website. Yandex.Probki uses a ten-point scale calibrated individually for each city and also provides functions for statistical analysis and short-term forecasting.

The goal is to establish a quantitative relationship between the sample score and the air quality.

\section{DISCUSSION OF THE RESULTS}

As a result of the quarantine and self-isolation, the traffic volume in Moscow decreased in the summer and winter of 2020. According to Mosekomonitoring data, in the week after the beginning of the quarantine (data for March 31, 2020), the maximum concentration of pollutants (carbon monoxide and sulfur dioxide) fell by a factor of 5-5.5. In the city center, the mean carbon monoxide concentration fell by a factor of three. Thus, the quarantine was an unplanned green initiative.

The data sent from the monitoring stations to the Mosekomonitoring website permits tracking of the change in concentration of pollutants such as nitrogen dioxide, sulfur dioxide, and particulates. We investigate the area around the Shchelkovo highway at different times (before the construction of alternative routes, after their construction, and during self-isolation). After the construction of alternative routes, traffic on the Shchelkovo highway fell, and the mean speed rose. That almost halved the pollutant concentration. This indicates a correlation between the monitoring results and the city's traffic congestion.

In Fig. 1, we show the traffic congestion during quarantine. We note a sharp fall: for a long period, the congestion score was zero. When restrictions eased, however, the situation began to return to normal: by the end of May, the congestion score was 5-6.

Another factor affecting the traffic congestion in Moscow is the time of day: in particular, there are morning and evening rush hours. The day of the week also matters: the difference in traffic volume between weekdays and weekends may be 400000 vehicles, while vehicle speed may differ by a factor of two or more.

The weather also plays a role. Holdups are greatest on days with heavy rain or snow [8]. Snow and the approach of the holidays mean that December is the worst month for traffic. The New Year vacation has the lightest traffic: the congestion score rarely exceeds $1-2$.

According to Mosekomonitoring data, the mean monthly air concentration of $\mathrm{NO}_{2}$ close to the highway in $2020\left(\mathrm{mg} / \mathrm{m}^{3}\right)$ was 0.0376 in January, 0.0499 in February, 0.0478 in March, 0.0345 in April, and 0.0385 in May. The mean monthly air concentration of $\mathrm{SO}_{2}\left(\mathrm{mg} / \mathrm{m}^{3}\right)$ was 0.0021 in January, 0.0027 in February, 0.0034 in March, 0.0020 in April, and 0.0028 in May. According to Yandex.Probki data, the mean monthly congestion scores for 2020 were 4 in January, 7 in February, 5 in March, 0 in April, and 3 in May. Analysis indicates that the change in atmospheric levels of nitrogen dioxide and sulfur dioxide is directly correlated with the change in traffic congestion (Fig. 2).

Thus, if we take account of all the relevant factorsrush hours, days of the week, season of the year-we 


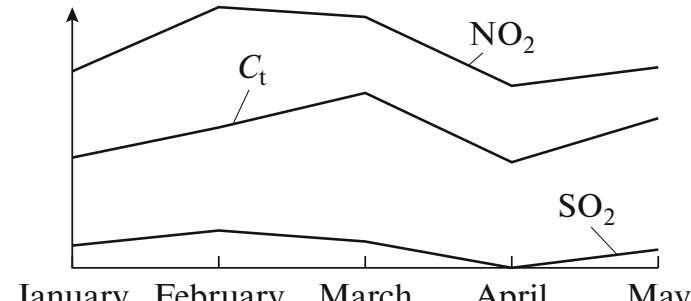

Fig. 2. Relation between the mean monthly atmospheric concentrations of $\mathrm{NO}_{2}$ and $\mathrm{SO}_{2}$ and the traffic congestion $C_{\mathrm{t}}$.

\begin{tabular}{|c|c|}
\hline \multicolumn{2}{|c|}{$\begin{array}{l}\text { Automated environmental monitoring } \\
\text { module in smart transportation system }\end{array}$} \\
\hline \multicolumn{2}{|c|}{$\hat{\imath}$} \\
\hline \multicolumn{2}{|c|}{ Pollution monitoring } \\
\hline \multicolumn{2}{|c|}{$\begin{array}{l}\text { atmospheric pollution } \\
\text { soil pollution near roads } \\
\text { water pollution } \\
\text { impact on urban ecosystem }\end{array}$} \\
\hline Weather conditions & \multirow{2}{*}{$\begin{array}{c}\text { Traffic } \\
\text { conditions }\end{array}$} \\
\hline temperature & \\
\hline $\begin{array}{l}\text { wind speed and direction } \\
\text { precipitation, humidity } \\
\text { cyclones, anticyclones, } \\
\text { inversions }\end{array}$ & $\begin{array}{l}\text { time of day } \\
\text { day of the week } \\
\text { road structure }\end{array}$ \\
\hline
\end{tabular}

Fig. 3. Environmental monitoring module in a smart transportation system.

may assess and predict the pollutant content in the atmosphere on the basis of the congestion scores.

Accordingly, we see that environmental monitoring of transportation is much less difficult on the basis of Yandex.Probki data.

There is a quantitative relationship between the congestion score and the pollutant emissions of traffic. That permits reliable prediction of air pollution.

\section{ENVIRONMENTAL MONITORING MODULE}

The environmental monitoring module for use in the smart transportation system is shown in Fig. 3.

For environmental prediction, we need models of the relation between the air pollution index and the congestion score, which, in turn, depends on the weather conditions, the time of day, the day of the week, and the state of the road network.

\section{REFERENCES}

1. Sorokin, A.V., Sotnikova, E.V., and Grafkina, M.V., Environmental criteria of the impact of automobile transport on the depositing environment of recreational areas, Bezop. Zhiznedeyat., 2015, no. 8 (176), pp. 45-51.

2. Belyavskii, A.E., Sorokin, A.E., and Khaustov, A.I., Head-up display systems in aviation, Russ. Eng. Res., 2021, vol. 41, no. 1, pp. 61-63.

3. Dmitrienko, V.P., Sotnikova, E.V., and Krivoshein, D.A., Ekologicheskaya bezopasnost' $v$ tekhnosfere: Uchebnoe posobie (Ecological Safety in Technosphere: Manual), St. Petersburg: Lan', 2016.

4. Belyavskii, A.E., Novikov, S.V., Sorokin, A.E., and Shangin, I.A., Thermal stores in spacecraft heating systems, Russ. Eng. Res., 2019, vol. 39, no. 6, pp. 507-509.

5. Belyavskii, A.E., Heat stores with a melting working medium for spacecraft thermal control systems: simulation, Russ. Eng. Res., 2020, vol. 40, no. 12, pp. 11351137.

6. Sotnikova, E.V., Sorokin, A.E., Bulychev, S.N., and Kalpina, N.Yu., Improved environmental monitoring for road transportation, Russ. Eng. Res., 2020, vol. 40, no. 12, pp. 1144-1146.

7. Sorokin, A.E., Bulychev, S.N., Novikov, S.V., and Gorbachev, S.I., Information science in occupational safety management, Russ. Eng. Res., 2019, vol. 39, no. 4, pp. 324-329.

8. Borshev, N.O., Sorokin, A.E., and Belyavskii, A.E., Mutual influence of capillary pumps in heat-pipe systems with different evaporator loads, Russ. Eng. Res., 2019, vol. 39, no. 9, pp. 782-784.

Translated by B. Gilbert 